\title{
Examination of the Semiotic Meaning of Characters Established by the Wu Zetian(則天武后)
}

\author{
측천무후가 제정한 문자의 기호학적 의미 고찰 \\ Joo-Eun Lee ${ }^{1}$ \\ 이주은 1 \\ ${ }^{1}$ Resercher, China Research Institute,Yon-Sei University, Korea, jel2000@hanmail.net
}

\begin{abstract}
This paper is aimed to examine the theories and concepts of various aspects of literature, ranging from rhetoric, semiotics, and furthermore, to hermeneutics. It attempted to re-examine in terms of semiotics as a universal concept faithful to principles and concepts rather than a review of letters established by China's only empress of the time. In the future, it will also be necessary to explore Chinese literature with a semiotic approach. In addition, as a symbolic system, it is believed that a closer review of the function and role of language characters with disclosure and communication should be conducted rather than viewing language and characters.
\end{abstract}

Keywords: Chinese Chracters, Semiotics, Interpretation, Rhetoric, Communication

요약: 본고에서는 수사학과 기호학, 더 나아가 해석학에 이르기까지 문자학에 대한 여러 면모를 폭넓게 고찰해 보고자 이론과 개념 위주로 살펴보았다. 당대의 중국 유일의 여황제인 측천무후가 제정한 문자에 대한 고석보다는 원리와 개념에 충실한 보편적 개념으로서의 기호학적 측면에서 재조명해 보고자 시도하였다. 앞으로 중국 문자학에 있어서 기호학적인 접근으로 탐구해 보는 것도 필요할 것이다. 또한 상징과 기호 체계로서 의미의 완전체로서 언어와 문자를 보기보다는 공시성과 통시 성을 가진 언어 문자로서의 기능과 역할에 대한 좀 더 면밀한 검토가 이루어져야 할 것이라고 사료된다.

핵심어: 중국문자학, 기호학, 수사학, 해석, 소통

\section{1. 서론}

우리가 현재 사용하고 있는 기호나 부호의 체계는 매우 실용성에 입각해서 디자인하고 있는 것 같다는 생각을 지울 수가 없다. 그러나 중국에서 최초의 한자의 초기 자형이 되었던 갑골문에서부터 오늘의 자체에 이르기까지 그 변천 과정이나 변화가 있었다. 소위 말하는 한자의 이체자(異體字)도 기호학적인 측면에서 생각해 본다면, 한 층 더 진일보된 연구가 될 것이라고 생각된다.

중국의 유일한 여황제인 측천무후는 집권 시절에 자신의 이름에 들어간 ⿱宀子子를 포함하여 14 자를 다시 제정하였다. 자신의 권력을 더 강화하기 위해서 일수도 있겠지만 당시

Received: August 04, 2021; $1^{\text {st }}$ Review Result: September 21, 2021; $2^{\text {nd }}$ Review Result: November 11, 2021 Accepted: December 31, 2021 
문헌들을 살펴보면, 측천무후가 문학적인 소양이 뛰어나다는 평도 있다[1]. 하지만 본 논고에서는 기호학적 관점에서 어떻게 접근해 갈 수 있는지 재조명해보고자 하였다. 역사적 문학적 관점에서 한 차원 더 발전적인 단계로 나아가, 측천무후가 새롭게 제정한 문자가 기호학적 관점에서 어떻게 바라볼 수 있는지 초고(初考)를 해보았다. 이는 문자학적인 관점에서도 의미가 있다고 사료된다. 이에 먼저 기호학적 관점에서 고찰해보고 의미론과 수사학적 접근 방법도 고려해 보고자 한다.

\section{2. 기호학적 관점에서의 고찰}

\section{1 기호학적 관점}

기호학 연구가 막 시작된 1970년대, 기호학의 사명이 '전달' 인가 ‘의미작용' 인가라는 논쟁이 있었다. 기호학을 소쉬르의 명령을 따라 아직 기호론(semiologie, semiology)이라 부르던 시절이라, 이 당시에는 기호학을 '커뮤니케이션의 기호론(semiology de in communication)' 과

'의미작용의 기호론(semiology de in signification)' 으로 나누는 것이 대세이었다. 전달은 의미작용을 전제로 하고, 의미작용 역시 소통 과정의 일부인 것이다. 기호학은 태생 배경과 정의 자체에서 언어 이상의 대상을 가지며, 반대로 언어학은 기호학의 한 부분, 즉 '언어 기호학' 인 것이다[2].

따라서 일부 학계, 특히 국내의 미학이나 문화 과학계에서 주장하는바 "기호학은 언어모델의 틀에서 벗어나지 못한다" 는 견해는 궁극적으로는 기호학의 창시자가 설파한 기호의 구성 원리나 기호학의 인식론적 구조에 대한 오해에서 비롯된 것으로 보인다.

\section{2 문자학의 발견}

소쉬르 사상 연구 분야에서 큰 획을 그은 김성도는 『로고스에서 뮈토스』에서 현대 기호학의 시원에 관한 새로운 이야기를 들려주었다. 소쉬르가 생각한 기호학의 연구대상으로 문자가 가장 중요한 대상으로 설정되어 있으며, 소쉬르의 자필 원고에서도 기호학적 관점에서 문자를 언급한 부분은 빈번히 나타난다[3].

글과 그림의 관계를 규명하고자 할 때 가장 먼저 봉착하게 되는 것은 '그림' 에서 시작된 문자의 시원과 발전 과정이다. '문자학' 이라 명명할 수 있는 해당 영역을 시각 기호학의 하위 영역으로 편입함으로써 시각 기호학의 외연을 넓힐 필요가 있다[4].

문자를 기호나 부호로 보는 관점은 그다지 보편적이지 않으나, 기호를 통하여 공간에서 표현됨으로 인하여 그 가치나 유용성은 크다고 보여진다. 지금도 중국의 운남성에서는 소수민족인 납서족이 사용하는 언어문자인 “동파문자(東巴文字)” 를 보면, 상당히 원시적이며 상형성이 짙음을 알 수가 있다. 의사소통 수단으로서의 기호나 부호의 역할이 그만큼 중요하다고 생각된다.

중국의 암각화에서 발견된 꽃 그림은 현재 사용되고 있는 중국어에서의 “華” 로서, 꽃이 흐드러지게 피어있는 모양을 나타낸 그림이다. 번영을 나타내는 꽃이 화사하게 피어있는 모습을 상형화해서 중국이란 나라를 표현할 때, 中華民國에서 “華” 로 쓰이게 되었다. 현재 우리가 사용하고 있는 “花(꽃 화)” 는 나중에 꽃을 대체할 단어가 없기에 새롭게 만든 자이다. 


\section{3 의미론과 해석학}

의미론은 언어의 의미를 다루는 학문인데, 그 의미가 무엇인지는 매우 철학적인 문제이기도 하다. 의미론 역시 기호학적으로 충분히 해명할 가능성이 열리는 것이기에 중요하다고도 볼 수 있다. 그 가능성을 확실하게 실현한 기호학자로 그레마스를 들 수 있다. 그레마스가 제시한 모델은 '의미생성행로' 라는 것인데, 그는 심층으로부터 표층을 거쳐 담화 차원에 이르는 과정에서 의미가 생성한다고 주장한다. 그의 기호의미론은 기호학의 이론을 의미론의 영역으로 확장했다는 점에서 의미가 있다. 기존의 음운론의 단위를 의미론적으로 확장하는 과정에서 의소나 동위소와 같은 새로운 개념을 만들었으며, 의소 간의 관계를 규정하기 위해

'기호사각형' 이라는 모델을 만들었다.

그가 제안한 의미생성행로는 의미가 발생하는 과정을 층위별로 보여줌으로써 의미가 형이상학적인 본질이 아니라, 언어학적 진행 과정임을 증명했다. 신화학에도 깊은 관심을 보였으며 말년에 퐁타니유와 함께 정념의 기호학을 정초했다. 그의 새로운 용어들은 매우 난삽하지만, 최근 많은 기호학자가 이를 텍스트 분석에 적용하여 일반화하는 추세에 있다. 여기서 주목할 점은 의미를 '언어를 초월한 영역에 있는 어떤 형이상학적 본질' 로 보는 것이 아니라, '기호작용을 통해 생성되는 과정' 으로 규정한다는 것이다. 실제로 이것은 기호학의 중요한 특성을 보여주는 핵심적인 문제이다[5].

그레마스가 말한 의미생성행로에 따르면 '학교' 의 의미는 심층으로부터 비롯된 어떤 보편적인 논리가 작동하여 표층을 통해 담화에서 발생하는 것이기 때문에, 독사(doxa)가 형성될 여지가 애초에 존재하지 않게 되는 것이다. 그저 관습적으로 형성된 견해를 따르는 것으로, 이는 모든 것을 당연시하는 방식이기 때문에 바로 거기서 잘못된 의사소통이 발생하게 되는 것이다. 의미를 탐구한다는 점에서 해석학 역시 의미론과 유사하지만, 해석학은 말이 어떤 맥락에서 내포하게 되는 의미를 더욱 중시한다. 해석학은 글을 읽는 독자가 그 텍스트의 의미에 깊숙이 관여한다는 점을 인정한다는 점에서 의미론(semantics)의 영역을 벗어나 화용론(pragmatics)의 영역으로 다가가게 된다[5].

\section{4 측천무후가 제정한 한자 자형}

중국의 유일한 여황제였던 당나라의 측천무후는 새로운 한자를 만들어 반포했다.

송나라 정초(鄭樵)의《육서략(六書略)》에 의하면 총 18 자를 창제하였다.

정초(鄭樵)가 제시한 글자 이외에도 ⿹ㅗㅇ (ㄱ)이나 月의 이체자인 등이 존재하는 것을 보면, 실제로는 20 여 자 이상이 창제되었을 것으로 보인다. 이들 글자는 측천무후 생존 당시에는 사용되었으나 모두 도태되고 측천무후 자신의 이름으로 사용되던 쑹 (照)자만 남게 되었다[6].

[그림 1] 에서 상단의 20 字가 측천무후가 새롭게 제정한 문자이고, 하단의 20 字는 각각 그에 대응하는 漢字들이다.

먼저 측천무후에 관한 당시의 문자관을 살펴보기 위해서 먼저 고대 중국사회에서의 언어 문자관은 어떻게 되는지 살펴보고자 한다. 


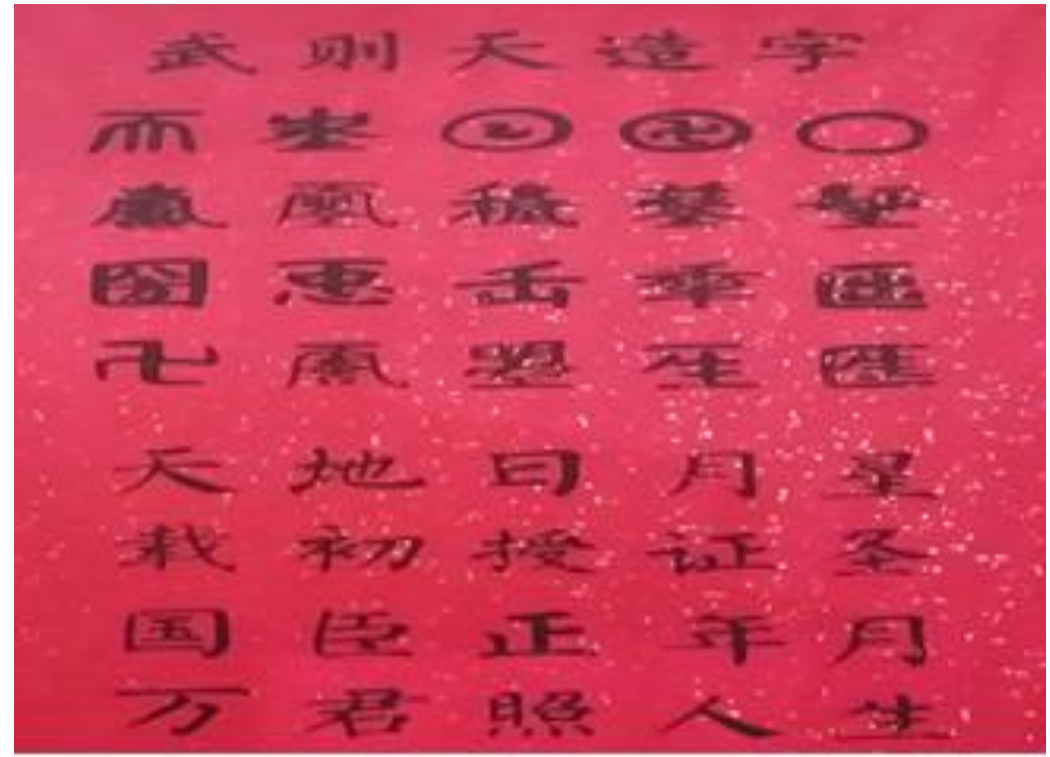

[그림 1] 측천무후가 새롭게 제정한 문자

[Fig. 1] A Newly Established Character by the 則天武后

\subsection{1 商나라의 언어 문자관}

인류가 처음으로 언어를 사용한 역사에 대해 검증하기는 어렵지만, 인류가 문자를 이용해서 자신의 의사 표현을 하기 시작한 것은 약 5 천 년 전 고대문명이 발생하면서부터 일 것이다. 甲骨文字는 일종의 신성문자(神聖文字;hieroglyphs)로서 당시 신정통치神政統治를 하던 왕조의 통치자들이 하늘의 상제上帝와 소통하여 자신들의 정치적인 통치권위를 인정받기 위한 점복나의 수단이었다[7].

商代까지 甲骨文字는 왕의 통치 수단이었으며, 文字에는 본래부터 주술의 힘을 가지고 있다고 여겼다. 원시적인 상태를 벗어나 제정일치의 시대에 들어선 商나라의 지배계급들은 文字를 통해서 하늘로부터 계시를 받았다는 명분을 내세우면서 그들 통치의 정통성을 보장받으려고 하였던 것을 알 수 있다.

갑골문의 巫와 祝은 이러한 예를 잘 나타낸다.

갑골문의 巫( I )는 무술을 행하는 데 필요한 도구의 상형이며, 금문의 서(萎 $)$ 자는 두 손에 조형의 도구를 잡고 점을 치는 동작이다. 서筮는 두 손으로 시초著草나 혹은 죽책竹策을 연산하여 점을 치는 방법을 표시하고 있다. 商代의 조는 생전에는 특이한 능력이 있어서 신과 통할 수 있었으므로 존경받는 사람이었으며, 사후에도 신령이 되어 제사를 받았다. 商代 卜辭에서는 흔히 巫에게 제사를 올리고 바람이 잘지를 묻고 있으니, 분명히 조는 풍우를

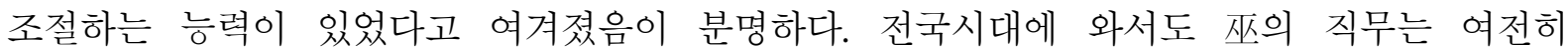
춤으로 비를 빌어 가뭄을 해소하고, 질병을 고치며, 喪事나 제사 시에 귀신과의 연락을 맡고 있었다[7].

갑골문의 祝( ${ }^{\top}$ 궉 $)$ 자는 한 사람이 조상의 신위 앞에 꼻어앉아 입을 벌리기도 하고 복을 구하는 것 혹은 두 손을 앞으로 내밀고 기도하는 모습을 본뜨고 있다. 祝은 문헌에서 대부분 기도한다는 동사로 쓰였으며, 기도하는 대상도 선조의 신령을 위주로 하고 있다. 《주례》小祝에 언급된 기도를 올리는 범위는 복과 풍년을 기원하고 때 아닌 비나 강풍, 질병 등을 막기 위한 것이었다[8]. 


\subsection{2 숌나라의 언어문자관}

중국의 고대왕조인 商나라는 상제上帝로부터 甲骨文字를 통해서 통치의 계시를 받고자 했다. 商代에는 하늘에 세상 만물을 주재하는 상제上帝가 있다고 여기고 주술적인 점복⺊ㅁㅇㅣ 일상적으로 행해졌다. 그러나 주周 황실에서는 하늘天로부터 그들 왕조의 정통성을

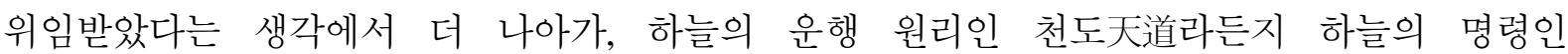
천명天命을 받았다고 하는 정통성을 내세우며 인문적인 통치질서를 지향하였다[7].

주周나라에서는 천天은 "지극히 높고 그 위는 없다는 뜻이며, 일-과 대大가 합하여진 글자이다.(至高無上, 從一大.)” 라고 풀이하였다. 즉 인간 세상을 상징하는 대大의 위를 가리키는 긴 획을 그어 지극히 높은 존엄한 하늘이라는 자연물로 보고자 했다. 따라서 하늘의 명령인 천명天命과 자연현상의 이치인 천도天道를 周나라의 통치이념으로 삼으려고 했다. 이처럼 周나라에 와서는 하늘을 인격신으로서가 아니라 존엄한 자연현상으로 보았다[7].

\subsection{3 설문해자說文解字와 왕권사상王權思想}

1) 王, 하늘 - 땅 · 사람이 통하다.

王, 천하가 귀속되는 곳이다. 동중서는 '고대에 문자를 만드는 사람이 세 개의 가로획을 긋고 그 가운데를 연결하고는 王이라고 하였다. 三은 天 · 地 · 人이며 이 셋을 서로 소통시키는 사람이 왕이다' 라고 王자를 해석하였다. 공자는 '하나로 셋을 연결하는 것이 王이다’ 라고 하였다(《1篇上 · 王部》: 王, 天下所歸往也. 董仲舒曰: ‘古之造文者, 三畫而連其中謂之王. 三者，天·地·人也，而參通之者王也.’ 孔子曰: ‘一貫三爲王.’ ).

王자에 대한 허신의 해석은 비판을 받기도 하였다. 그 자형분석과 해석이 모두 봉건통치를 옹호하는 입장에서 출발하여 대노예주를 과대포장하고 찬양하는 것이라고 비판한 것이다. 허신이 인용한 王자에 대한 동중서의 해석은 『춘추번로』에 나온다.

고대에 문자를 만드는 사람이 가로획 세 개를 긋고 그 가운데를 연결하여 王이라고 하였다. 이 세 획은 하늘 - 땅 - 사람을 대표하며, 그 가운데를 관통시킨 것은 그 세 가지의 이치를 통하게 한 것이다. 천지와 사람을 취하고 이 셋을 통하게 하는 것, 이것을 왕이 아니고서야 그 누가 감당할 수 있겠는가(《春秋繁露 - 王道通三 》: 古之造文字者, 三書而連其中謂之王. 三畫者，天地與人也，而連其中者，通其道也. 取天地與人之中以瓜而參之，非王者其孰能當是.).

동중서는 서한西漢의 유학자로 漢 景帝 때에 박사博士를 지냈다. 그는 신권 정치론을 제기하여 황제가 나라를 다스리는 정치 상황에 따라서 하늘이 상서로운 징조와 재난으로 지지와 징벌을 내릴 것이라고 주장하였다. 또한 “道의 큰 근원은 하늘에서 나온다. 하늘이 변하지 않으면 도道역시 변하지 않는다” 는 형이상학적 관점을 제기하였다. 그가 대책비이웅을 통해 군권신수君權神授와 천인감응天人感應의 사상을 피력한 목적은 왕권을 신성화하는 데 있었다.

2) 王의 초기자형에 대한 학자들의 견해로 살펴본 왕권주의

王자의 갑골문과 금문의 대표 자형을 살펴보면, 갑골문은 $₫, \mathbb{E}$, 금문은 I· I· J $\cdot I_{\text {ol }}$ 있다. 갑골문과 금문의 시기에는 규범자형이 정해져 있지 않았으므로 여러 다른 형태의 자형이 공존하였다. 갑골문과 금문의 王자의 형태를 보면 가로획이 반드시 세 개만 있는 것은 아니며 세로획도 | 의 형태만 있는 것은 아니다. 따라서 현존 최초의 한자인 갑골문에 
근거하면 王이 본래 '천지인, 이 셋을 하나로 이어서 통하게 하는 자가 왕이다(一貫三爲王)' 라는 의미를 담아서 구성된 글자가 아님을 알 수 있다.

王의 초기 자형에 대한 학자들의 견해는 분분하다. 청대淸代 오대징못大澂은 王의 초기자형이 불을 나타낸 것으로 보고 ‘불이 땅 속에서 뿜어져 나오는 형태' 라고 하였으며, 왕국유王國維도 이 의견을 따랐다. 서중서徐中舒는 王자가 '사람이 두 손을 모으고 단정하게 앉아있는 형상' 이라고 하였고 오기창몸其昌과 임운林蕓은 '도끼' 의 형상을 나타낸 것이라고 하였다. 이들의 견해는 모두 나름의 근거가 있기 때문에 그중 한 가지를 선택해서 명확하게 무엇이라고 단정할 수는 없다. 그러나 王자의 갑골문 및 금문의 문자자료와 '一貫三' 이라는 王자에 대한 자형해석을 연결시킬 수 없다는 것만은 분명하다. 자원 字源해석의 측면에서 ‘一貫三爲王” , ‘王者, 往也’ 라는 해석을 평가한다면 인정받지 못하겠지만 철학과 사상 면에서 본다면 유의미한 해석이라고 할 수 있다[9].

\section{3. 측천무후가 제정한 문자의 기호학적 의미}

기호(Sign)를 통해 대상(Object)에서 해석체(Interpretant)로 전달되는 것은 형식(Form)이다. 즉 형식은 실존과는 전혀 다른 것이다. 그것은 힘(Power)이며, 어떤 것이 특정 조건 속에 일어날 것이라는 사실이다. 이러한 형식(Form)은 대상을 통해 실제로 체현된다. 이는, 형식(Form)이 대상 속에 존재하기에, 형식을 구성하는 조건적 관계가 형식에 관계될 것이라는 것을 의미한다. 기호에서 형식은 재현적 의미로만 체현된다(embodied). 이는, 어떤 실제적인 기호(Sign)의 변형에 의한 것이든지 아니든지, 기호(Sign)는 해석체에 전달하는 힘을 부여받게 되었다는 것을 의미한다[10].

『일반언어학 강의』에서 소쉬르는 '구조' 라는 말을 별로 쓰지 않았으며, 썼다 해도 그것을 구조주의의 의미에서 사용하지 않았다. 그에 상응하는 것으로 그가 사용한 개념은 오히려 '체계(system)' 였다. 여기에서 중심적 역할을 담당하는 개념은 '가치(value)' 의 개념으로서, 언어의 기호 가치는 관계, 특히 동일한 체계 내에 있는 다른 기호와의 대립에서 나온다는 것이다. 여기에서 도출되는 결론은 "언어는 실질(substance)이 아니라 형식(form)” 이라는 것이다. 아마도 이러한 인식은 이후 구조주의 뿐 아니라 후기구조주의와 포스트모더니즘의 발전에까지 영향을 끼친 가장 핵심적인 것이라 할 수 있을 것이다[11].

소쉬르가 발견한 언어의 이분법적 구조 중에 중요한 나머지 한 가지는 '공시성(synchrony)' 과 '통시성(diachrony)' 이다. 하나의 '빠롤' 이 '결합체' 로서 어떤 메시지를 전달한다면 그것의 기표에 결합된 기의는 현재의 언어 공동체에서 통용되는 의미이다. 언어에 스며 있는 현재라는 시간의 속성을 '공시성' 이라 한다. 한편 특정 기표와 결합하는 기의는 상황에 따라 달라질 수도 있지만 역사적으로도 변화한다. 특정 기표에 결합하는 기의의 역사적 변화 현상을 언어의 통시성이라 한다. 물론 어떤 언어 공동체에서 현재 통용되는 의미는 과거의 의미들을 바탕으로 하고 있다고 할 수 있다. 그런 점에서 현재 사용되는 언어는 그때마다 항상 통시성과 공시성의 교차 지점에 있다고 할 수 있다[11].

이는 코드를 결정하는 요소인 '과거의 경험과 현재의 상황' 과 상통하는 점이 있다. 따라서 측천무후가 제정한 문자도 공시성과 통시성의 두 가지 맥락에서 모두 살펴 보아야 할 것이다.

먼저 공시적인 의미로 살펴본다면, 권력과 통치와의 관계들을 고찰해 보아야 할 것이다. 거대한 나라의 통치를 위해서는 권력을 장악하는 수단으로서, 문자가 사용되었을 수도 있다고 
보아야 할 것이다. 이는 당시 권력을 반대하는 입장에 있는 세력들을 무마시키고 하나의 권력과 통치 아래에 두기 위한 하나의 방법이 될 수도 있을 것이다. 마치 진시황제가 문자를 통일한 것처럼 측천무후 역시 자신이 집권하는 동안 그 세력을 하나로 집약시키기 위한 방편으로 그렇게 했을 수도 있다고 보여진다.

그 다음으로는 통시적인 의미로 살펴본다면, 한시적이라 볼 수 있겠다. 갑골문자가 귀족 계층에서 당시 점을 치기 위한 수단으로 사용되어진 것이라면, 서민층과 대중적인 호흡을 함에 있어서는 그 가치를 보장할 수 없었던 것처럼 측천무후가 제정한 문자에 있어서도 그리 대중적이지는 못했던 것 같다. 또한 현세에까지 사용되어지지 않고 사라진 문자로만 보기에는 그 당시 권력계층에 대한 특히 중국 최초이자 유일무이한 여황제라는 위치에 걸맞지 않게 퇴보적인 발언이 될 수도 있다. 그러함에도 불구하고 대중성이라든가 당시 집권 계층간에 소통의 부재에서 오는 편협적인 사고의 발상에서 제정된 문자라면 그 수명은 그리 길지 못하는 것도 당연한 일이 될 것이다. 이에 논고에서는 기호학적인 관점에서 이를 어떻게 접근할 수 있는 지 그 접근 방법으로서 고찰을 시도해 본 것이라 할 수 있겠다.

앞으로 공시성과 통시성을 함께 볼 수 있는 안목으로서의 중국 문자에 대한 개념이 점차로 바뀌어져 가야 할 것이다. 한시적으로만 사용되어졌던 문자는 그 역사적 의미나 역할이 변변치 않을 수도 있다. 그럼에도 측천무후라는 당대의 남성 편력까지 가진 중국 유일의 여황제가 군림을 하기 위해서 여러 수단과 방법을 동원했다는 흔적으로까지 남을 수 있을 만큼 문자 재정비를 위한 노력을 게을리 하지 않았다는 점은 높이 살 만하다. 앞으로 수사학과 해석학에 이르기까지 중국 문자에 대한 다각도적인 측면에서의 고찰이 필요하다고 보인다.

\section{4. 한국 효제도(孝悌圖)와 비교 고찰}

기호로서의 이미지 해석이 가능한 것은 사회 구성원들 간에 축적된 약호들이 존재하기 때문이다. 다시 말해 사회적 인식 약호 속에 기호의 운용능력이 존재한다. 그러므로 작품해석이란 미술가를 둘러싸고 있는 지적, 심리적, 사회적 약호뿐만 아니라 수용자의 정신을 이루고 있는 여러 약호들이 상호작용하여 이루어지는 것이라 할 수 있다.

한자문화권 중에서 유독 조선이 창출하고 폭넓게 수용했던 문자도가 있는데, 이것이 바로 효제도(孝悌圖) [그림 2]이다. 조선 시대의 민화 문자도는 크게 세종류로 “첫째는 용(龍), 호(虎), 구(龜) 등 수호적 상징문자, 둘째는 부귀(富貴), 수복강녕(壽福康寧), 다남(多男) 등 부귀와 길상을 뜻하는 문자와 그것들을 응용한 문자 그림 그리고, 셋째는 효제도(孝悌圖)라 불리는 효(孝), 제(悌), 충(忠), 신(信), 예(禮), 의(義), 염(廉), 치(恥)의 8폭 문자도 병풍이다[12]. 효제도의 발생은 지배층이 가치를 둔 유교윤리가 감계(鑑戒) 및 교화(敎化)를 목적으로 백성에게 정책적으로 유포되면서, 그 핵심적 의미를 함축한 8자의 이해를 전제로 하고 있다. 글을 모르는 일반 백성을 위한 이해의 방법으로 택한 것은 흥미 유발과 '기억' 이다.

즉, 15 세기부터 18 세기까지 지속해서 보급된 관찬교화서(官撰教化書)인 효자도, 행실도는 효자, 충신, 열녀 등에 관한 모범사례(주로 중국인물)를 사건별로 '삽화그림[住]+이야기 설명[從]' 으로 구성함으로써, 보는 재미가 있는 이미지로 기억에 남는 장치를 마련한 것이다. 물론 식자층에게는 기억을 위한 구체적 이야기나 시각적 이미지 없이 8자의 가치를 이해하고 이를 미학적으로 표현하는 수준이 가능했을 것이다[12]. 

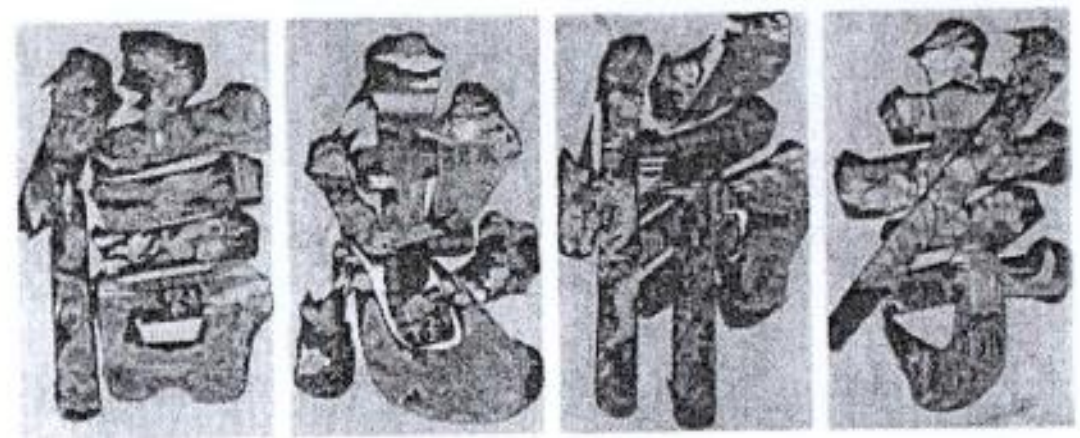

[그림 2] 한국의 효제도 1

[Fig. 2] Korea's Filial Piety, Respect Painting 1
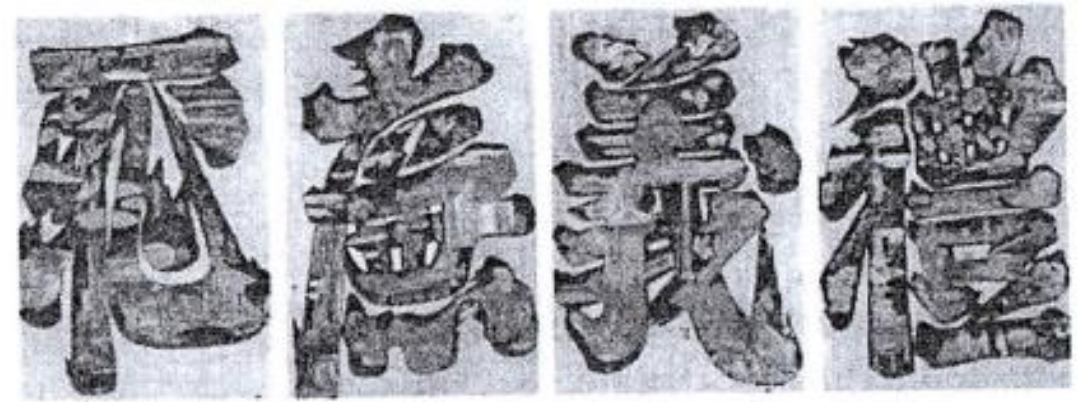

[그림 3] 한국의 효제도 2

[Fig. 3] Korea's Filial Piety, Respect Painting 2

중국의 유일한 여황제인 측천무후가 남긴 문자와 한국의 문자도를 비교해 볼 때, 교화와 집권의 목적으로 만들어진 기호문자로 보기에는 언어학적 측면에서 좀 더 깊은 이해가 필요하다는 생각이 들었다. 이에 본고에서는 문자마다 의미를 두고 고찰하기보다는 전체적인 언어 담화 맥락에서 또 기호학적인 측면에서 다루고자 하였다.

중국에서도 거대한 제국을 통치하기에 필요한 교화의 목적으로 효제도나 행실도와 같은

것을 백성들에게 보급할 수도 있었겠지만, 진시황제의 문자통일과 같은 일이 미리 이 시대에 일어난 것은 아닌가 하는 생각이 든다. 우리가 현재 살펴볼 수 있는 언어학적 측면에서의 접근도 물론 중요하지만 통시성과 공시성 모두를 다각적으로 살펴보아야 할 필요가 있다고 판단이 되어, 기호학적 측면에서 이론을 통하여 접근해 보고자 하였다. 아직 미숙한 논문이지만, 앞으로 재고의 가치가 십분 있다고 여겨져 논문의 주제를 선정하고 이에 따라 자료를 찾아보았다. 이론과 실제에서 다소 차이가 있을 수 있다. 시간이 많이 흐른 뒤에 다시 옛 자료를 찾아보고 현재 유추해 보는 작업이 중요하지만, 이를 통하여 당시 측천무후가 집권을 위하여 문자 통일을 시도했다는 것과 함께 그만큼 문자에 대한 애착도 강했음을 고려해 볼 수 있을 것 같다.

현대에 이르기까지 기존 자료의 탐색을 통하여 당대의 문자로 새로이 제정한 14자의 언어학적 고찰과 함께 역사적, 문자학적 의미의 고찰을 더 이루어져야 할 것으로 보인다. 이에 먼저 언어학적인 측면에서 살펴보고 이어서 역사적, 문자학적 고찰로 이어진 연구가 될 수 있기를 바란다. 후세에 남겨진 문자 중에서 갑골문이나 동파문자와 같은 상형성이 짙은 문자가 아니기에 사실, 문자로 보아야 할 것인지 아니면 개인이 제정한 문자 자체로 보아야 
할 것인지 그 또한 다시 재고해 보아야 할 것이다.

\section{5. 결론}

본고에서는 수사학과 기호학, 더 나아가 해석학에 이르기까지 문자학에 대한 여러 면모을 폭넓게 고찰해 보고자 이론과 개념 위주로 살펴보았다. 당대의 중국 유일의 여황제인 측천무후가 제정한 문자에 대한 고석(古釋)보다는 원리와 개념에 충실한 보편적 개념으로서의 기호학적 측면에서 재조명해보고자 시도하였다. 물론 초기 연구이기에 부족함이 많다. 하지만 앞으로 중국 문자학에서 기호학적인 접근으로 탐구해 보는 것도 필요할 것이다. 또한 상징과 기호 체계로서의 또 의미의 완전체로서 언어와 문자를 보기보다는 공시성과 통시성을 가진 언어문자로서의 기능과 역할에 대한 좀 더 면밀한 검토가 이루어져야 할 것이다.

측천무후가 제정한 자형을 의미론과 해석학적 입장에서 분석하면서, 주관적인 입장이 되지 않으려고 했으나, 역시나 근거 있는 자료를 가지고 분석하기에는 어려운 점이 많았던 것 같다. 중국의 암각화에서 발견된 중화민국의 “華” (꽃이 흐드러지게 피어있는 모양을 묘사) 가 원래는 꽃이 흐드러지게 피어있는 모양이었기에 번영과 영화를 상징하는 단어로 중국을 나타내는 단어로 쓰이자, 실제로 꽃을 나타내는 “花” 를 다시 제정하여 사용한 것 또한 같은 맥락에서 해석할 수 있을 것이다. 이처럼 부호나 기호를 우리의 판단이나 잣대가 아닌, 관념론의 입장에서 한층 더 면밀히 검토해 볼 필요도 있다고 사료된다.

\section{6. 감사의 글}

본고 논문은 한국연구재단 시간강사 연구지원 추경사업 (2019S1A5B5A07105057)의 연구지원을 받아 작성된 논문임.

\section{References}

[1] Ahn Jung-hoon, A Study of Ze-tian Wu-hou(則天武后)'s conception about letter-worship, Chinese Literature, (2004), Vol.41, pp.45-62, UCI: G704-000174.2004.41..001

[2] R. Barthes, Rhetorique de I'image, Communications, (1964), Vol.4, pp.40-51.

[3] Kim Seongdo, Lecture on Modern Symbolism, Minumsa, pp 83-96, (1998)

[4] Park Ilwoo, A Preparatory Research for establishing the Visual Semiotics as autonomous discipline, Semiotic Inquiry, (2016), Vol.47, pp.65-104, UCI: G704-001064.2016.47..007

[5] Song Hyo-seop, Humanities, Talking about Semiotics Semiotics, Lee Soo-p, pp.38-41, (2013)

[6] Ha Young-sam, Eliminating negative and sinister Chinese characters - Cultural psychology behind variants, Chinese Literature Research, (2019), No.75, pp.381-418, DOI: 10.31985/JCL.75.14

[7] Moon Seung-yong, A study on the cultural historical significance in the view of language and character of all philosophers in the Spring and Autumn Warring States Period, Chinese Studies Research, (2019), No.88, pp.149-178, DOI: $10.36493 / J C S .88 .6$

[8] Heo Jin-woong, Chinese Ancient Society, translated by Hong Hee, Dongmunseon, p.535, (2003)

[9] Wang Ning, Xie Dung Yuen, Liu Phang Zhu，說文解字 and Chinese Ancient Culture, translated by Kim Eun-hee, Hakgobang, pp.67-81, (2010)

[10] James Jakob Liszka, transferred by Lee Yoon-hee, Understanding Perth Semiotics, Hankuk University of Foreign 
Examination of the Semiotic Meaning of Characters Established by the Wu Zetian(則天武后)

Studies Knowledge Press, p.75, (2013)

[11] Jeon Dongyeol, Semiotics, Yonsei University Press, pp.32-38, (2005)

[12] Yoo Hong-joon, Moonja-do, Daewonsa, pp.23-28, (1993) 